$\underline{\text { Review Article }}$

\title{
ROLE OF BIOMARKERS IN EPILEPTOGENESIS: A CONCISE REVIEW
}

\author{
ATUL A. BARAVKAR ${ }^{*}$, SAGAR D. SHINDE ${ }^{1}$, NITIN B. AHER ${ }^{2}$ \\ ${ }^{1}$ Agricultural Development Trust's Shardabai Pawar Institute of Pharmaceutical Sciences and Research, Baramati, India, ${ }^{2}$ Ashvin College \\ of Pharmacy, Sangmaner, India \\ Email: atul200678@gmail.com \\ Received: 05 Oct 2021, Revised and Accepted: 26 Nov 2021
}

\begin{abstract}
Epilepsy is a gathering of ongoing neurological problems described by intermittent, unconstrained, and unusual seizures. It is one of the most widely recognized neurological messes, influencing a huge number of individuals around the world. A biomarker is characterized as a dispassionately estimated normal for an ordinary or obsessive natural interaction. Recognizable proof and legitimate approval of biomarkers of epileptogenesis, the improvement of epilepsy, and ictogenesis, the affinity to create unconstrained seizures, may foresee the improvement of an epilepsy condition; recognize the presence and seriousness of tissue equipped for producing unconstrained seizures; measure movement after the condition is set up; furthermore, decide pharmacoresistant. Such biomarkers could be utilized to make creature models for more savvy screening of potential antiepileptogenic and antiseizure medications and gadgets and to lessen the expense of clinical preliminaries by enhancing the preliminary populace and going about as proxy markers to abbreviate the preliminary span. The destinations of the biomarker subgroup for the London Studio were to characterize approaches for distinguishing conceivable biomarkers for these reasons. Examination to recognize dependable biomarkers may likewise uncover basic instruments that could serve as helpful focuses for the improvement of new antiepileptogenic and antiseizure compounds.
\end{abstract}

Keywords: Epilepsy, Biomarker, Seizures, Ictogenesis

(C) 2022 The Authors. Published by Innovare Academic Sciences Pvt Ltd. This is an open access article under the CC BY license (https://creativecommons.org/licenses/by/4.0/ DOI: https://dx.doi.org/10.22159/ijpps.2022v14i1.43306. Journal homepage: https://innovareacademics.in/journals/index.php/ijpps.

\section{INTRODUCTION}

The treatment of epilepsy is principally pharmacological and, in a limited handful, careful. Treatment relies upon analysis, which, thusly, relies upon the event of epileptic seizures, discontinuous occasions with the significantly related hazard of bleakness and mortality [1]. Analysis and treatment of epilepsy experience the absence of reliable biomarkers for either epileptogenicity, the presence and seriousness of an epilepsy condition, or then again epileptogenesis, the turn of events and progression of an epilepsy condition [2]. There is, thusly, no real way to authoritatively analyze epilepsy until seizures show up or to survey the adequacy of a therapeutic intercession other than the experimentation approach of holding on to check whether another seizure will happen [3]. Limitation of the epileptogenic district for careful resection requires broad and expensive symptomatic testing [4]. Additionally, there is no approach to decide if epilepsy will result from a potential epileptogenic affront, for example, extreme head injury or intracranial disease, or on the other hand, create in a patient inclined to a hereditary type of epilepsy, or to foresee if an epilepsy disorder will be reformist and pharmacoresistant. It is valuable here to recognize the terms 'biomarker' and 'substitute marker'. While a biomarker is characterized as a dispassionately estimated normal for an ordinary or pathological natural interaction [5, 6]. For epilepsy, the initial step is to build up solid biomarkers of two abnormal organic cycles: epileptogenicity and epileptogenesis, so this is the subject of the following articles. It is expected that once established, some biomarkers will be helpful as substitute markers of infection for helpful trials, yet dependable biomarkers and proxy markers can likewise fill other significant needs in analysis and examination. Paradoxically, a 'hazard factor' is a variable related to an expanded probability of a sickness interaction, yet it's anything but a solid marker. Febrile seizures, head injury, and positive family ancestry are hazard factors for epilepsy, in any case, are not biomarkers [7]. Aiming at finding the most relevant articles for this review, a thorough, comprehensive web search was conducted by consulting the PubMed, Scopus, ELSEVIER-EMBASE, Cochrane Library, Google Scholar, and the Web of Science databases, as well as from the personal archive of the author collected between 2007 to 2021, using the keywords: epilepsy, epileptogenesis, biomarkers, neurons, etc. The language of the article was not restricted. The titles from the search results were evaluated closely and determined to be acceptable for potential inclusion criteria. Also, references from the selected articles were examined as further search tools.

Table 1: Various important biomarkers for epilepsy

\begin{tabular}{lllll}
\hline Biomarker type & Use & Tissue & Method & Biomarker \\
\hline Diagnostic & Epilepsy & Serum & Molecular analysis & has-miR-106b-5p \\
Diagnostic & Refractory epilepsy & Serum & Molecular analysis & has-miR-301a-3p \\
Prognostic & Hyperthermia induced epilepsy & Brain & MRI & T2 relaxation time \\
Diagnostic & Focal epilepsy & Plasma & Molecular analysis & CCL17 \\
Diagnostic & Tissue epilepsy & Brain & Scalp EEG & High-frequency oscillations \\
Diagnostic & Temporal lobe epilepsy & Brain & MRI & White matter fractional anisotropy \\
\hline
\end{tabular}

\section{The demand for epilepsy biomarkers}

The improvement of drug specialists and gadgets to treat, fix, and forestall epilepsy would benefit extraordinarily from the ID of conclusive biomarkers fit for reducing the cost of disclosure and approval of new treatments for epilepsy [8]. In principle, biomarkers may work with the advancement of mediations to forestall epilepsy; furthermore, to forestall the event of epileptic seizures, turn around the movement of epilepsy, and conceivably even fix epilepsy after it is set up. Albeit apparently more uncertain, biomarkers could be 
utilized to distinguish and adequately treat pharmacoresistant epilepsy. In patients for whom no epileptogenic injury is recognized or whose EEG demonstrates no proof of epileptic form action, biomarkers are subtle [9]. For sure, our ability to anticipate seizure repeat after a first seizure-or foresee advancement of epilepsy after analysis of a possibly epileptogenic neurological affront (e. g., awful cerebrum injury and intracerebral discharge)-is very restricted if the MRI and EEG are unrevealing [10].

\section{Parts of epilepsy to focus for biomarker revelation}

The instruments answerable for the advancement of epilepsies and the age of unconstrained intermittent seizures are in all likelihood multifactorial [12]. Seizure edge, which is a unique idea, changes ordinarily over the long haul; for example, seizure limit can be subject to the diurnal cycle and, in ladies, on the period [13]. The current enemy of seizure drugs raises the seizure edge and in this way, lessens the penchant for seizures to happen. Explicit epileptogenic irregularities may likewise change over time with the goal that the potential for a seizure might be expanded or diminished relying upon an assortment of physiological factors. Epileptogenic anomalies can be hereditary or primary/metabolic, and their recognizable proof might prompt specific and centered treatments [14]. A few transient elements can encourage epileptic seizures and subsequently decide exactly when they happen. At the point when these encouraging elements are promptly evident, like blazing lights in a person with photosensitive epilepsy, aversion is a significant part of general consideration [15]? Biomarkers connected to an encouraging variable could be valuable for seizure expectation and the conceivable advancement of failed intercessions. For most patients, be that as it may, the character of encouraging variables is obscure [16]. The assortment of potential instruments and the diverse calculated parts of epileptogenesis and ictogenesis recommend various conceivable biomarker targets [17].

How an exhaustive arrangement of biomarkers could work with clinical preliminaries

Right now, approval of mediations expected to forestall epilepsy would be restrictively costly because, even with the most extreme possibly epileptogenic affront, just a few patients foster epilepsy, and this might require $\geq 10 \mathrm{y}$ [18]. Thus, a clinical preliminary would require a huge subject populace and a long length of follow-up. The biomarkers could dependably anticipate which patients would eventually foster epilepsy; the preliminary populace could be enhanced with subjects who have a high probability of creating epilepsy, consequently significantly lessening the expense. Contrasted with movement or abatement, the biomarkers showed in could hypothetically archive that a fix or counteraction had happened from the get-go throughout the preliminary. The length of the clinical review could then be considerably diminished, coming about in a doable and financially savvy preliminary plan [19]. Additionally, other biomarkers might work with preliminaries against seizure mediations, enormously lessening the expenses for approving new medications and gadgets for pharmacoresistant epilepsy, or even foresee the improvement of pharmacoresistant [20].

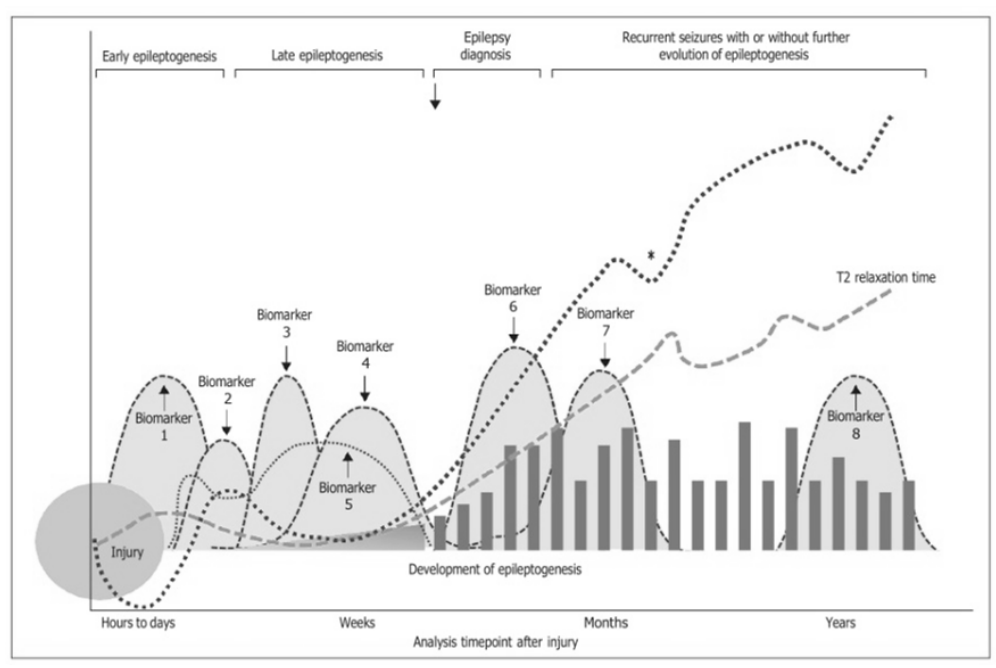

Fig. 1: Relation between the set of biomarkers and time dependence [11]

\section{The amplitude of epileptogenesis biomarkers}

On account of epilepsy, biomarkers can change from imaging and electrophysiological estimations to changes in quality articulation and metabolites in blood or tissues [21]. The key is that their essence or levels relate to a particular part of the illness. For instance, a given biomarker may relate to the advancement of epilepsy following a head injury, be that as it may, may at this point don't be available once the epileptic issue is completely evolved. A focal objective is distinguishing proof of the full reach or range of conceivable biomarkers that are dependable and exceptionally prescient of who has or will foster epilepsy [22]. A significant thought is whether a biomarker is obtrusive or non-intrusive. For instance, while a spinal liquid test could be exceptionally prescient, acquiring spinal liquid is an intrusive strategy that could extraordinarily restrict its utilization clinically and for clinical preliminaries [23]. All things considered, an exceptionally prescient attractive reverberation imaging (MRI) or electroencephalogram (EEG) biomarker would be more adequate. As depicted over, a basic thought is the 'window' when the biomarker is communicated corresponding to the sickness [24]. For instance, on account of epileptogenesis, it is basic to know when after a head injury or stroke, the biomarker first shows up and how long it endures. When the epilepsy condition is set up and the patient is having intermittent seizures, know how the biomarker changes in the preictal, ictal, postictal, and interictal states [25]. Different contemplations that could balance biomarker levels are states are known to balance seizures, for example, rest wake state just as age and sexual orientation. Distinguishing epilepsy biomarkers will require exact, quantitative estimations in condition-fitting creature models and patients with explicit epilepsy disorders in planned and review examine [26].

\section{Stages of recognition of biomarkers used for epilepsy}

The revelation interaction is summed up in Stage I (revelation) incorporates the essential scan procedure for ID of the biomarker up-and-comer and a proof-of-idea study showing that it is communicated in an in vivo creature model. Stage II (confirmation) incorporates tests that show the handiness of the biomarker in subject definition and additionally expectation of treatment reaction. Stage III (interpretation) incorporates the meaning of insignificant 
necessities for a trial that is expected to interpret the biomarker found in preclinical models to human use [27].

\section{Stage I-revelation}

Search system-In which species should the essential revelation of the biomarker for human epileptogenesis be finished? Rodents, fish, worms, people, or in silica approaches were considered practical. Nonetheless, early confirmation of the biomarker articulation in human tissue is significant. Tissue tests from either in vivo or in vitro models could be utilized in the essential disclosure of biomarker upand-comers [28]. No prioritization was done between enormous scope atomic profiling (for example, lipidomics, proteomics, miRNome) approach over pathology specific search technique. It was noticed that probably more than one biomarker is required, which may address biomarkers inside a similar investigation stage (e. g., a few biochemical markers) or markers from various investigation stages (e. g., a plasma biomarker joined with an imaging marker) [29]. The incorporation of an electrophysiological marker into the biomarker stage would almost certainly expand the particularity of the stage to epileptogenesis. In the following stage, one needs to choose which models to use to choose-perhaps from tens or many up-and-comers-a markers for additional investigation [30]. The Working Group (WG) suggestion is to offer inclination to sub-atomic biomarkers that can be estimated in the blood instead of the cerebrum or cerebrospinal liquid (CSF) [31]. In essential screening, factors like the effectiveness of the examination or the size of the adjustment of a marker level were not thought of significant. Although the WG expected the real factors identified with the investigation of biomarkers in people, the WG inferred that obtrusiveness in testing, potential confusions in testing, cost, the time needed for test assortment or investigation, burden, or affectability to continuous drug ought not to preclude the conceivable biomarker applicant at the early revelation stage [32]. It was, in any case, noticed that if the biomarker up-and-comer is communicated in other CNS infections not related to epilepsy, it might diminish the particularity of the biomarker to epileptogenesis.

\section{Stage II-confirmation}

As tolerant populaces are heterogeneous, a basic inquiry is a way generalizable the biomarker is. This makes a question: the number of models ought to be tried to exhibit that a picked biomarker applicant dependably predicts epileptogenesis? It was viewed as that in a positive case, the biomarker would work in more than one model. In any case, one ought not to ignore a biomarker that would work in one model, as it were. The investigation ought to demonstrate the presence versus nonattendance of the marker in various test gatherings (epileptogenesis versus non-epileptogenesis) and a distinction in the gathering means and changeability [33]. Additionally, the affectability that's more, the explicitness of the biomarker ought to be tried. Like in a proof-of-idea study, a fleeting profile of the biomarker articulation ought to be considered. For atomic and cell biomarkers, blood, mind, CSF, salivation, or skin could fill in as tissue for examination. The particularity of biomarkers for finding or epileptogenesis just was not considered basic [34]. The equivalent biomarker could anticipate additionally, for instance, the advancement of co-morbidities. Nonetheless, it was noticed that reliance of biomarker articulation on the confinement of epileptogenic zone, sort of pathology, natural rhythms, or conditionrelated issues (for example, those that could impact biomarker freedom) ought to be thought of. Additionally, the commitment of fringe tissue to biomarker levels ought to be noted [35].

\section{Stage III-interpretation}

What starter examination ought to be done in people before applying the biomarker inferred from creatures considers in human preliminaries of potential antiepileptogenic mediations [36]. As demonstrated before, the declaration of the biomarker applicant ought to be affirmed right on time in the measure, that is, in the verification of-idea testing stage. It was considered attainable to gather tests and perform another testing equal from creatures and people. Moreover, one ought to evaluate the reproducibility of information inside the research facility, between labs, utilizing diverse test strategies and various models [37].

\section{CONCLUSION}

Considering that the course of epileptogenesis may unfurl over months, a long time, or even many years, it is difficult to imagine a benchmark group sufficiently strong to represent the heap factors that may affect infection movement over the long haul. Maybe an ideal way to tackle this problem is to aggregate epilepsy patients in as significant attention to little subtleties as could be expected and limit biomarker studies to limit aggregates. For instance, to decide the meaning of autoantibodies in central epilepsy pharmacoresistance, the exploratory gathering ought to be a gathering of counteracting positive agent participants with comparable sorts of seizures, comparative localization (e. g., mesial fleeting projection beginning), and comparative age of beginning, epilepsy length and imaging discoveries; the control gathering would likewise have epilepsy with amazingly comparable clinical and segment attributes, distinguished exclusively by the shortfall of the immune response in question.

\section{FUNDING}

The author(s) received no financial support for this work and/or publication of this article.

\section{AUTHORS CONTRIBUTIONS}

All authors have contributed equally.

\section{CONFLICTS OF INTERESTS}

\section{Declared none}

\section{REFERENCES}

1. Stafstrom CE, Carmant L. Seizures and epilepsy: an overview for neuroscientists. Cold Spring Harb Perspect Med. 2015 Jul;5(6):(a022462). doi: 10.1101/Csh Perspect.a022426, PMID 26033084.

2. Jerome EJ, Pitkanen A, Loeb JA, Dudek EF, Bertram EH, Cole AJ, Moshe SL, Wiebe S, Fuerman BE, Jensen FE, Mody I, Nehlig A, Vezzani A. Epilepsy biomarkers. Epilepsia. 2013 Aug;54(4):61-9.

3. Bone I, Dein S. Religion, spirituality, and epilepsy. Epilepsy Behav. 2021 Sep;122:108219. doi: 10.1016/j.yebeh. 2021.108219, PMID 34343961.

4. Tufenkjian K, Lüders HO. Seizure semiology: its value and limitations in localizing the epileptogenic zone. J Clin Neurol. 2012 Dec;8(4):243-50. doi: 10.3988/jcn.2012.8.4.243, PMID 23323131.

5. Sechidis K, Papangelou K, Metcalfe PD, Svensson D, Weatherall J, Brown G. Distinguishing prognostic and predictive biomarkers: an information-theoretic approach. Bioinformatics. 2018 Oct;34(19):3365-76. doi: 10.1093/ bioinformatics/ bty357, PMID 29726967.

6. Engel J, Pitkänen A. Biomarkers for epileptogenesis and its treatment. Neuropharmacology. 2020;167:107735. doi: 10.1016/j.neuropharm.2019.107735. PMID 31377200.

7. Samprathi M, Jayashree M. Biomarkers in COVID-19: an up-todate review. Front Pediatr. 2021 Mar;8:1-12. doi: 10.3389/fped.2020.607647, PMID 607647.

8. Goldenberg MM. Overview of drugs used for epilepsy and seizures: etiology, diagnosis, and treatment. P T. 2010 Jul;35(7):392-415. PMID 20689626.

9. Kirmani BF, $\mathrm{Au} \mathrm{K,} \mathrm{Mir} \mathrm{S,} \mathrm{Hogan} \mathrm{M,} \mathrm{Kim} \mathrm{D,} \mathrm{Sharma} \mathrm{P.}$ Biomarkers for epileptogenesis in patients with autoimmune epilepsy. NN; 2020. doi: 10.20517/2347-8659.2020.29.

10. Vespa PM, McArthur DL, Xu Y, Eliseo M, Etchepare M, Dinov I, Alger J, Glenn TP, Hovda D. Nonconvulsive seizures after traumatic brain injury are associated with hippocampal atrophy. Neurology. 2010 Aug;75(9):792-8. doi: 10.1212/WNL.0b013e3181f07334, PMID 20805525.

11. Pitkanen A, Loscher W, Vezzani A, Becker AJ, Simonato M, Lukasiuk K, Grohn O, Bankstahl JP, Friedman A, Aronica E, Gorter JA, Ravizza T, Sisodiya SM, Kokaia M, Beck H. Advances in the development of biomarkers for epilepsy. Lancet Neurol. 2016 Jul;15(8):843-56. doi: 10.1016/S1474-4422(16)00112-5, PMID 27302363.

12. Nagarathnam M, Vengamma B, Shalini B, Latheef SAA. Stigma and polytherapy: predictors of quality of life in patients with 
epilepsy from south India. Ann Indian Acad Neurol. 2017 Sep;20(3):233-41. doi: 10.4103/aian.AIAN_36_17, PMID 28904455.

13. Quigg M, Smithson SD, Fowler KM, Sursal T, Herzog AG, NIH Progesterone Trial Study Group. Laterality and location influence catamenial seizure expression in women with partial epilepsy. Neurology. 2009 Jul;73(3):223-7. doi: 10.1212/WNL.0b013e3181ae7adf, PMID 19620611.

14. Yu JY, Pearl PL. Metabolic causes of epileptic encephalopathy. Epilepsy Res Treat. 2013 May;2013:124934. doi: $10.1155 / 2013 / 124934$.

15. Mead MN. Benefits of sunlight: a bright spot for human health Environ Health Perspect. 2008 Apr;116(4):A160-7. doi: 10.1289/ehp.116-a160, PMID 18414615.

16. Alkhidze M, Lomidze G, Kasradze S, Tsiskaridze A Characteristics and predictive biomarkers of drug-resistant epilepsy- study in Georgia. NN. 2017 Sep;4(9):191-8. doi: 10.20517/2347-8659.2017.14

17. Petrillo S, Pietrafusa N, Trivisano M, Calabrese C, Saura F, Gallo MG, Bertini ES, Vigevano F, Specchio N, Piemonte F. Imbalance of systemic redox biomarkers in children with epilepsy: role of ferroptosis. Antioxidants (Basel). 2021 Aug;10(8):1-13. doi: 10.3390/antiox10081267, PMID 34439515.

18. Pitkanen A, Ekolle Ndode Ekane X, Lapinlampi N, Puhakka N. Epilepsy biomarkers- Toward etiology and pathology specificity. Neurobiol Dis. 2019 Mar;123:42-58. doi: 10.1016/j.nbd.2018.05.007, PMID 29782966.

19. Budikayanti A, Chaliana C, Louisa M, Setiabudy R. Development and validation of carbamazepine plasma concentrations measurement and its application on epilepsy patients. Int J Pharm Pharm Sci. 2017 Jul;9(9):1-5.

20. Jerome EJ. Approaches to refractory epilepsy. Ann Indian Acad Neurol. 2014 Mar;17;Suppl 1:S12-17.

21. Lukasiuk K, Becker AJ. Molecular biomarkers of epileptogenesis. Neurotherapeutics. 2014 Apr;11(2):319-23. doi: 10.1007/s13311-014-0261-6, PMID 24566938.

22. Niemantsverdriet E, Valckx S, Bjerke M, Engelborghs $S$. Alzheimer's disease CSF biomarkers: clinical indications and rational use. Acta Neurol Belg. 2017 Jul;117(3):591-602. doi: 10.1007/s13760-017-0816-5, PMID 28752420.

23. Shimizu S, Hirose D, Hatanaka H, Takenoshita N, Kaneko Y, Ogawa $\mathrm{Y}$, Sakurai $\mathrm{H}$, Hanyu $\mathrm{H}$. Role of neuroimaging as a biomarker for neurogenerative diseases. Front Neurol. 2018 Apr;9(265):1-6.

24. Glaba P, Latka M, Krause MJ, Kuryto M, Jernajczyk W, Walas W, West BJ. Changes in interictal pretreatment and post-treatment EEG in childhood absence epilepsy. Front Neurosci. 2020 Mar;14(196):1-9.

25. Cole JH, Marioni RE, Harris SE, Deary IJ. Brain age and other bodily 'ages': implications for neuropsychiatry. Mol Psychiatry.
2019 Jun;24(2):266-81. doi: 10.1038/s41380-018-0098-1, PMID 29892055

26. Höller Y, Nardone R. Quantitative EEG biomarkers for epilepsy and their relation to chemical biomarkers. Adv Clin Chem. 2021 Nov;102:271-336. doi: 10.1016/bs.acc.2020.08.004, PMID 34044912

27. Baraban SC. Emerging epilepsy models: insights from mice, flies, worms and fish. Curr Opin Neurol. 2007 Apr;20(2):164-8. doi: 10.1097/WC0.0b013e328042bae0, PMID 17351486.

28. Chen X, Chen H, Dai M, Ai J, Li Y, Mahon B, Dai S, Deng Y. Plasma lipidomics profiling identified lipid biomarkers in distinguishing early-stage breast cancer from benign lesions. Oncotarget. 2016 Jun;7(24):36622-31. doi: 10.18632/oncotarget.9124, PMID 27153558.

29. Simonato M, Agoston DV, Brooks Kayal A, Dulla C, Fureman B, Henshall DC, Pitkänen A, Theodore WH, Twyman RE, Kobeissy $\mathrm{FH}$, Wang KK, Whittemore V, Wilcox KS. Identification of clinically relevant biomarkers of epileptogenesis- a strategic roadmap. Nat Rev Neurol. 2021 Feb;17(4):231-42. doi: 10.1038/s41582-021-00461-4, PMID 33594276

30. Hirshi AP, Sethuraman M. Cerebrospinal fluid (CSF) analysis and interpretation in neurocritical care for acute neurological conditions. Indian Crit. Med. 2019 Jun;23;Suppl 2:S115-9.

31. Hayward KS, Schmidt J, Lohse KR, Peters S, Bernhardt J, Lannin NA, Boyd LA. Are we armed with the right data? Pooled individual data review of biomarkers in people with severe upper limb impairment after stroke. NeuroImage Clin. 2017 Sep;13:310-9. doi: 10.1016/j.nicl.2016.09.015, PMID 28053857.

32. Fish DR, Spencer SS. Clinical correlations: MRI and EEG. Magn reson imaging. 1995 Jan;13(8):1113-7. doi: 10.1016/0730725x(95)02020-t, PMID 8750324.

33. Atik A, Stewart T, Zhang J. Alpha-synuclein as a biomarker for Parkinson's disease. Brain Pathol. 2016 May;26(3):410-8. doi: 10.1111/bpa.12370, PMID 26940058.

34. Kanner AM, Mazarati A, Koepp M. Biomarkers of epileptogenesis: psychiatric comorbidities (?) Neurotherapeutics. $2014 \quad$ Apr;11(2):358-72. doi: 10.1007/s13311-014-0271-4, PMID 24719199.

35. Forrester SN, Zmora R, Schreiner PJ, Jacobs DR, Roger VL, Thorpe $\mathrm{RJ}$, Kiefe CI. Accelerated aging: a marker for social factors resulting in cardiovascular events? SSM Popul Health. 2021;13:100733. doi: 10.1016/j.ssmph.2021.100733. PMID 33532540.

36. Sojeetra N, Acharya R, Harisha Cr, Srivastava S, Misra A, Hegde S. Enetic barcoding and botanical studies on Pothos scandens $\mathrm{L}$. leaves-an extra-pharmacopoeial drug of Ayurveda. Int J Pharm Pharm Sci. 2021 Jun;13(8):1-9.

37. Li C, Ashlock JC, Wang X. Quantifying repeatability reproducibility sources of error and capacity of a measurement: demonstrated using laboratory soil plasticity tests. Adv Civ Eng. 2019 Jul;2019:111. doi: $10.1155 / 2019 / 4539549$, PMID 4539549. 